\title{
Noninvasive ventilation during walking in patients with severe COPD: a randomised
}

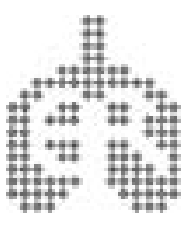
cross-over trial

\author{
M. Dreher, J.H. Storre and W. Windisch
}

ABSTRACT: It was hypothesised that noninvasive positive-pressure ventilation (NPPV) applied during walking prevents exercise-induced hypoxaemia and improves exercise performance in severe chronic obstructive pulmonary disease (COPD) patients already receiving long-term NPPV.

A total of 20 COPD patients (mean \pm SD age $65.1 \pm 8.7 \mathrm{yrs}$, forced expiratory volume in one second $27 \pm 8 \%$ predicted and total lung capacity $116 \pm 27 \%$ pred) reporting dyspnoea, even during mild exertion, underwent two 6-min walking tests with a rollator and supplemental oxygen $\left(2.1 \pm 0.9 \mathrm{~L} \cdot \mathrm{min}^{-1}\right)$ in a randomised cross-over design: with and without pressure-limited NPPV as used at home (inspiratory:expiratory pressure $2.9 \pm 0.44: 0.4 \pm 0.1 \mathrm{kPa}(29 \pm 4: 4 \pm 1 \mathrm{mbar})$, respiratory frequency $20 \pm 2$ breaths $\cdot \mathrm{min}^{-1}$ ).

The arterial oxygen tension significantly increased by $1.39 \pm 1.43 \mathrm{kPa}(95 \%$ confidence interval (Cl) $0.71-2.07 \mathrm{kPa})$ after walking with NPPV, but significantly decreased by $1.43 \pm 1.06 \mathrm{kPa}(95 \% \mathrm{Cl}$ $-1.92--0.94 \mathrm{kPa}$ ) without NPPV. Dyspnoea, as assessed by the Borg dyspnoea scale, significantly decreased from 6 (interquartile range (IQR) 4.5-10) to 4 (1.5-4.5) and walking distance significantly increased from 209 (IQR 178-279) to 252 (203-314) m when walking was NPPV-aided.

In chronic hypercapnic chronic obstructive pulmonary disease, high-intensity noninvasive positive-pressure ventilation can also be administered during walking with unchanged ventilator settings compared with settings used at rest, thus resulting in improved oxygenation, decreased dyspnoea and increased walking distance. Therefore, noninvasive positive-pressure ventilation during walking could prevent hypoxia-induced complications and could, in future, play a role in palliative care.

KEYWORDS: Dyspnoea, exercise, 6-min walking test, noninvasive positive-pressure ventilation, oxygenation, respiratory failure

$\mathrm{T}$ he most troublesome burden for patients with chronic respiratory failure (CRF) due to chronic obstructive pulmonary disease (COPD) is dyspnoea and exercise limitation. In these patients daily activities such as walking are associated with transient oxygen desaturations [1]. In addition, the cardiovascular comorbidity responsible for death is high in patients with COPD and CRF, who are at high risk of death from cardiovascular complications following exercise-induced hypoxia [2-4].

Noninvasive positive-pressure ventilation (NPPV) has been used as an aid to exercise training in COPD patients [5, 6]. NPPV is most often used in pulmonary rehabilitation. In this setting, NPPV has been shown to increase minute ventilation despite reduced inspiratory effort [7], to unload inspiratory muscles $[8,9]$ and to prolong exerciseinduced lactataemia [10], thus reducing dyspnoea on exertion and improving exercise tolerance [7, 11-17]. However, none of these studies focused primarily on patients with CRF already receiving NPPV for home mechanical ventilation (HMV), although these patients have the most severe limitations of physical activity and the highest risk of death from hypoxia-induced cardiovascular complications [2-4].

Therefore, the present study was aimed at testing the feasibility of NPPV application during walking in patients with severe COPD who were already on HMV. In addition, oxygenation has been shown to be significantly improved in patients already receiving NPPV for treatment of pulmonary tuberculosis sequelae, when NPPV was used during exercise compared with unaided exercise [18]. Therefore, it was hypothesised that the application of NPPV would result in the avoidance of exercise-induced hypoxaemia
AFFILIATIONS

Dept of Pneumology, University

Hospital Freiburg, Germany.

\section{CORRESPONDENCE}

W. Windisch

Dept of Pneumology

University Hospital Freiburg

Killianstrasse 5

D-79106 Freiburg

Germany

Fax: 497612703704

E-mail: wolfram.windisch@uniklinik-

freiburg.de

Received:

June 112006

Accepted after revision:

January 192007

\section{STATEMENT OF INTEREST}

Statements of interest for all authors of this manuscript can be found at www.erj.ersjournals.com/misc/ statements.shtml

European Respiratory Journa

Print ISSN 0903-1936

Online ISSN 1399-3003 
and the improvement of exercise performance, when added to supplemental oxygen compared with oxygen alone, in patients with severe COPD already receiving NPPV for long-term treatment. If so, NPPV might be a useful adjunct in daily life for patients with end-stage COPD.

\section{METHODS}

The study protocol was approved by the institutional review board for human studies of the Albert-Ludwig University, Freiburg, Germany, and was performed in accordance with the ethical standards laid down in the Declaration of Helsinki, 2000. Informed written consent was obtained from all patients.

\section{Patients}

COPD patients with hypercapnic CRF (stage IV according to the Global Initiative for Chronic Obstructive Lung Disease (GOLD) criteria [19]) reporting dyspnoea, even during mild exertion despite optimal treatment with anti-obstructive and anti-inflammatory medication, long-term oxygen therapy and HMV, were consecutively enrolled. Only stable patients were recruited. Patients who presented with an acute exacerbation (respiratory frequency $>30$ breaths $\cdot \mathrm{min}^{-1}$, $\mathrm{pH}<7.35$ or clinical signs of infection), those planned for weaning from invasive ventilation or those who had been intubated or tracheostomised during the previous 3 months were excluded. Further exclusion criteria were: bronchiectasis; post-tuberculosis sequelae; rib cage deformities; neuromuscular disorders; and bronchial carcinoma.

\section{NPPV}

NPPV was applied in a pressure-limited assist/control mode. Prior to the study, all patients had been carefully established on NPPV in hospital due to hypercapnic CRF. Thereby, ventilator settings had been chosen in order to maximally decrease elevated arterial carbon dioxide tension $\left(\mathrm{Pa}_{\mathrm{a}} \mathrm{CO}_{2}\right)$ levels, as described previously by the current authors [20-22]. Briefly, patients were on controlled NPPV at rest for most of the time, but the assist/control mode allowed patients to receive additional assisted breaths delivered by the machine if needed. Therefore, the most sensitive trigger threshold as individually tolerated with regard to the prevention of autotriggering was chosen for all patients.

A one-way circuit with an expiratory valve was used in 18 patients, and a silent flow exhalation valve (Weinmann, Hamburg, Germany) was used in two patients. For passive humidification a heat and moisture exchanger (Hygrovent $\mathrm{S}_{\mathbb{R}}$; Medisize bv, Hillegom, the Netherlands) was provided if necessary.

\section{Study design}

Lung function parameters (Masterlab-Compact ${ }_{\circledast}$ Labor; Jaeger, Hochberg, Germany) and inspiratory mouth occlusion pressures $\left(\mathrm{ZAN}^{100}\right.$; ZAN Gerätetechnik $\mathrm{GmbH}$, Oberthulba, Germany) were assessed at baseline, as previously described [23]. A standardised 6-min walking test (6MWT) [24] was performed with the following measurements: dyspnoea as assessed by the Borg dyspnoea scale (BDS) [25]; blood gases taken from the arterialised earlobe (AVL OMNI ${ }_{\circledast}$; Roche Diagnostics GmbH, Graz, Austria); blood pressure; cardiac frequency; and 6-min walking distance (6MWD). Blood gases were taken immediately before and after the 6MWT while breathing spontaneously with supplemental oxygen. In NPPVaided walking, patients were switched immediately after walking from NPPV to supplemental oxygen alone with subsequent measurements of blood gases. Patients were familiarised with the 6MWT. Resting during the $6 \mathrm{MWT}$ was allowed, but data was not further analysed. Two 6MWTs were performed in each patient in a randomised cross-over design on two consecutive days between 14:00-16:00 $\mathrm{h} \geqslant 6 \mathrm{~h}$ after cessation of nocturnal NPPV: one with supplemental oxygen alone and one with NPPV powered by internal battery in the addition to supplemental oxygen. For this purpose, a rollator (model 306194-2; Meyra, Kalletal, Germany) was used for both $6 \mathrm{MWTs}$ on which the ventilator and the oxygen tank were placed (fig. 1). The flow for supplemental oxygen and the ventilator settings used during walking were identical to the settings used at home and were not changed during the study.

\section{Statistical analysis}

Data are presented as mean \pm SD after testing for normal distribution (Kolmogorov-Smirnov test). In non-normally distributed data, the median and interquartile range (IQR) are indicated. The primary outcome parameter, which was the change in arterial oxygen tension $\left(\mathrm{Pa}_{2} \mathrm{O}_{2}\right)$ during 6MWT, served as the parameter determining the minimal sample size to ensure powerful testing on intervention. Assuming a power of $90 \%$ with an $\alpha$-error of 0.05 to detect a mean \pm SD change in $\mathrm{Pa}, \mathrm{O}_{2}$ of $1.86 \pm 1.39 \mathrm{kPa}$, according to previous findings [18] and the current authors' clinical experience, at least nine patients were needed for the analysis. In order to increase the power of the analysis, the target sample size was 20 patients. This sample size allowed more reliable generalisation of the findings and the ability to detect changes in secondary outcome parameters which were as follows: 6MWD; BDS; and $\mathrm{Pa}, \mathrm{CO}_{2}$ following 6MWT. Paired t-tests were used for the quantitative measurements, and the Wilcoxon signed-rank test was used for the BDS. For normally distributed data the $95 \%$ confidence interval (CI) was given if appropriate. Statistical significance was assumed for a p-value of $<0.05$.
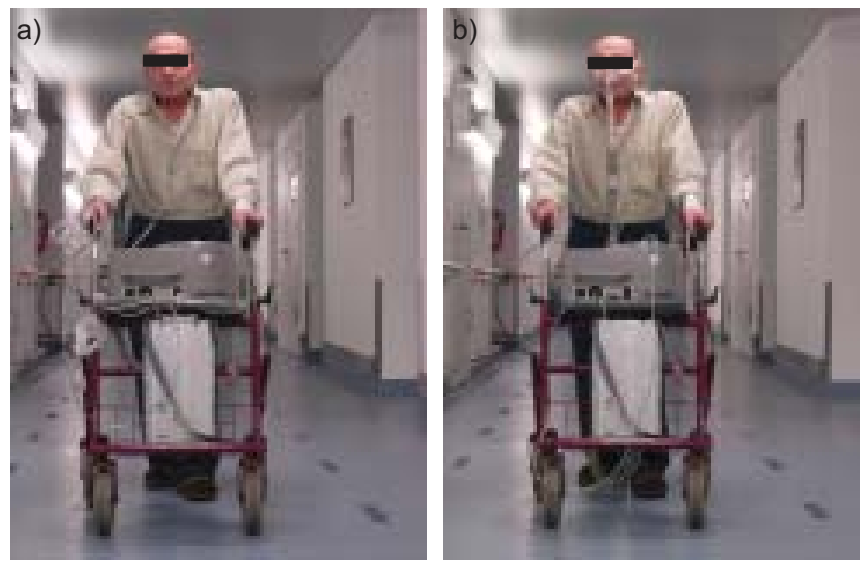

FIGURE 1. A chronic obstructive pulmonary disease patient during a 6-min walking test while on a) supplemental oxygen and b) noninvasive positivepressure ventilation in addition to supplemental oxygen. 


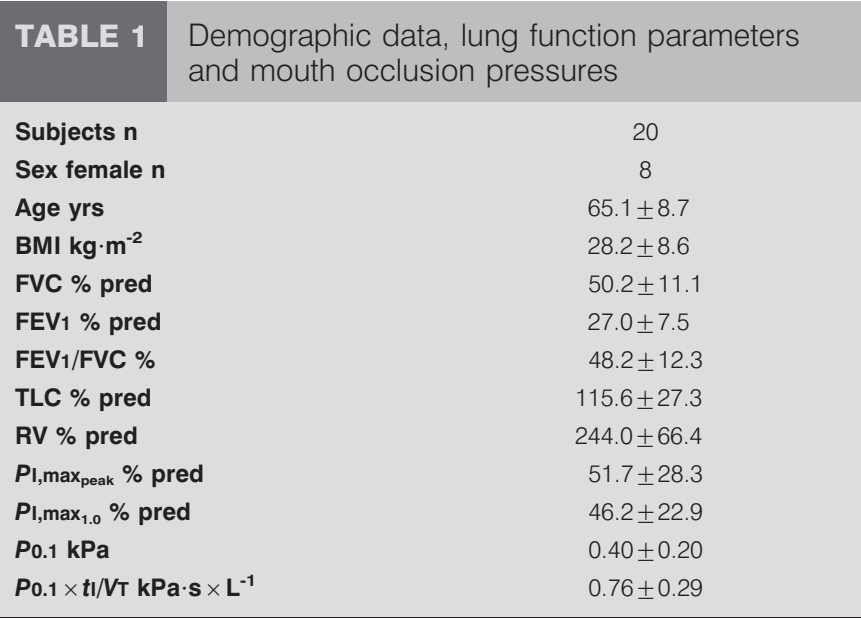

Data are presented as mean $\pm S D$, unless otherwise stated. BMI: body mass index; FVC: forced vital capacity; \% pred: \% predicted; FEV1: forced expiratory volume in one second; TLC: total lung capacity; RV: residual volume; PI,max peak: peak maximal inspiratory mouth pressure; $P$ I, max $_{1.0}$ : plateau maximal inspiratory mouth pressure sustained for $1 \mathrm{~s}$; $P 0.1$ : mouth occlusion pressure $0.1 \mathrm{~s}$ after onset of inspiration during normal breathing; $t \mathrm{l}$ : inspiratory time, $V_{T}$ : tidal volume.

\section{RESULTS}

In total, 20 patients completed the study and one patient refused to participate. All patients suffered from end-stage COPD with severe impairments of lung function parameters and mouth occlusion pressures (table 1). Significant comorbidity was evident: 14 subjects had arterial hypertension; seven had coronary heart disease; one had congestive heart failure; six had pulmonary hypertension; six had chronic atrial fibrillation; four had type- 2 diabetes mellitus; and six were obese (body mass index $>30 \mathrm{~kg} \cdot \mathrm{m}^{-2}$ ). Of the 20 patients, 19 had been heavy smokers with a mean cumulative smoking dosage of $50.0 \pm 26.4$ pack-yrs; however, 18 of them had given up smoking. During a routine control visit for NPPV 17 patients were studied, and three patients receiving HMV were studied during evaluation for lung transplantation. All patients subjectively reported severe dyspnoea during mild physical exertion. Two patients were receiving additional long-term oral morphine therapy with a daily dosage ranging 10-20 mg for the treatment of dyspnoea.

The mean duration of HMV used during the night and also intermittently during the daytime was $35.1 \pm 30.5$ months, and mean flow rate of supplemental oxygen was $2.1 \pm 0.9 \mathrm{~L} \cdot \mathrm{min}^{-1}$. NPPV was applied using Legendair (Airox, Pau Cedex, France), BREAS PV403 and BREAS VIVO 40 (Breas Medical AB, Molnlycke, Sweden) in 10, eight and two patients, respectively. Mean inspiratory positive airway pressure was $2.89 \pm 0.4 \mathrm{kPa}(28.9 \pm 4.4 \mathrm{mbar})$, mean expiratory positive airway pressure was $0.43 \pm 0.08 \mathrm{kPa}(4.3 \pm 0.8$ mbar $)$, mean respiratory frequency was $19.8 \pm 1.7 \mathrm{breaths} \cdot \mathrm{min}^{-1}$ and the mean inspiratory:expiratory ratio was 1:1.8. The Profile Light mask (Respironics Inc., Pittsburgh, PA, USA) was used as a nasal mask in seven patients and an individually built nasal mask was used in four patients. The Mirage full face mask

\section{TABLE 2 Blood gases, cardiac frequency $(f C)$, blood pressure, dyspnoea and walking distance before and after the 6-min walking test $(6 \mathrm{MWT})$.}

\section{Supplemental oxygen NPPV and supplemental oxygen $\quad$ Difference after 6MWT $\quad$ p-value} $95 \% \mathrm{Cl}$

\begin{tabular}{|c|c|c|c|c|}
\hline \multicolumn{5}{|l|}{ Before 6MWT } \\
\hline $\mathrm{Pa}_{1} \mathrm{O}_{2} \mathrm{mmHg}$ & $72.4 \pm 5.6$ & $70.7 \pm 8.1$ & & 0.16 \\
\hline $\mathrm{Pa}, \mathrm{CO}_{2} \mathrm{mmHg}$ & $50.4 \pm 5.7$ & $50.1 \pm 7.4$ & & 0.64 \\
\hline $\mathrm{Sa}_{1} \mathrm{O}_{2} \%$ & $95.1 \pm 1.6$ & $94.7 \pm 2.1$ & & 0.524 \\
\hline $\mathrm{pH}$ & $7.40 \pm 0.02$ & $7.40 \pm 0.03$ & & 0.33 \\
\hline$f C$ & $89.5 \pm 12.2$ & $87.6 \pm 15.7$ & & 0.67 \\
\hline SBP mmHg & $119.5 \pm 20.3$ & $122.6 \pm 17.2$ & & 0.49 \\
\hline DBP mmHg & $69.8 \pm 14.4$ & $70.4 \pm 12.6$ & & 0.85 \\
\hline BDS & $0(0 / 0)$ & $0(0 / 0)$ & & 0.63 \\
\hline \multicolumn{5}{|l|}{ After 6MWT } \\
\hline $\mathrm{Pa}_{1} \mathrm{O}_{2} \mathrm{mmHg}$ & $61.6 \pm 7.9$ & $81.2 \pm 12.4$ & $13.3-26.0$ & $<0.001$ \\
\hline $\mathrm{Pa}, \mathrm{CO}_{2} \mathrm{mmHg}$ & $53.3 \pm 6.5$ & $51.5 \pm 6.4$ & $-3.5--0.1$ & 0.038 \\
\hline $\mathrm{Sa}, \mathrm{O}_{2} \%$ & $88.8 \pm 4.0$ & $94.6 \pm 3.4$ & $3.7-7.9$ & $<0.001$ \\
\hline $\mathrm{pH}$ & $7.37 \pm 0.03$ & $7.38 \pm 0.03$ & NF & 0.21 \\
\hline$f C$ & $102.7 \pm 14.8$ & $101.5 \pm 13.3$ & $-10.0-7.7$ & 0.79 \\
\hline SBP mmHg & $133.7 \pm 24.2$ & $137.5 \pm 19.0$ & $-6.3-13.9$ & 0.44 \\
\hline DBP mmHg & $75.3 \pm 15.1$ & $80.6 \pm 12.1$ & NF & 0.034 \\
\hline BDS & $6(4.5-10)$ & $4(1.5-4.5)$ & & $<0.001$ \\
\hline 6MWD m & $222.0 \pm 84.8$ & $260.7 \pm 64.9$ & NF & 0.027 \\
\hline
\end{tabular}

Data are presented as mean \pm SD or median (interquartile range), unless otherwise stated. NPPV: noninvasive positive-pressure ventilation; $\mathrm{Cl}_{\text {: }}$ confidence interval; $\mathrm{Pa}_{\mathrm{a}} \mathrm{O}_{2}$ : arterial oxygen tension; $\mathrm{Pa}_{1} \mathrm{CO}_{2}$ : arterial carbon dioxide tension; $\mathrm{Sa}, \mathrm{O}_{2}$ : oxygen saturation; SBP: systolic blood pressure; DBP: diastolic blood presure; BDS: Borg dyspnoea scale; 6MWD: 6-min walking distance; NF: normality test failed. $1 \mathrm{mmHg}=0.133 \mathrm{kPa}$. 

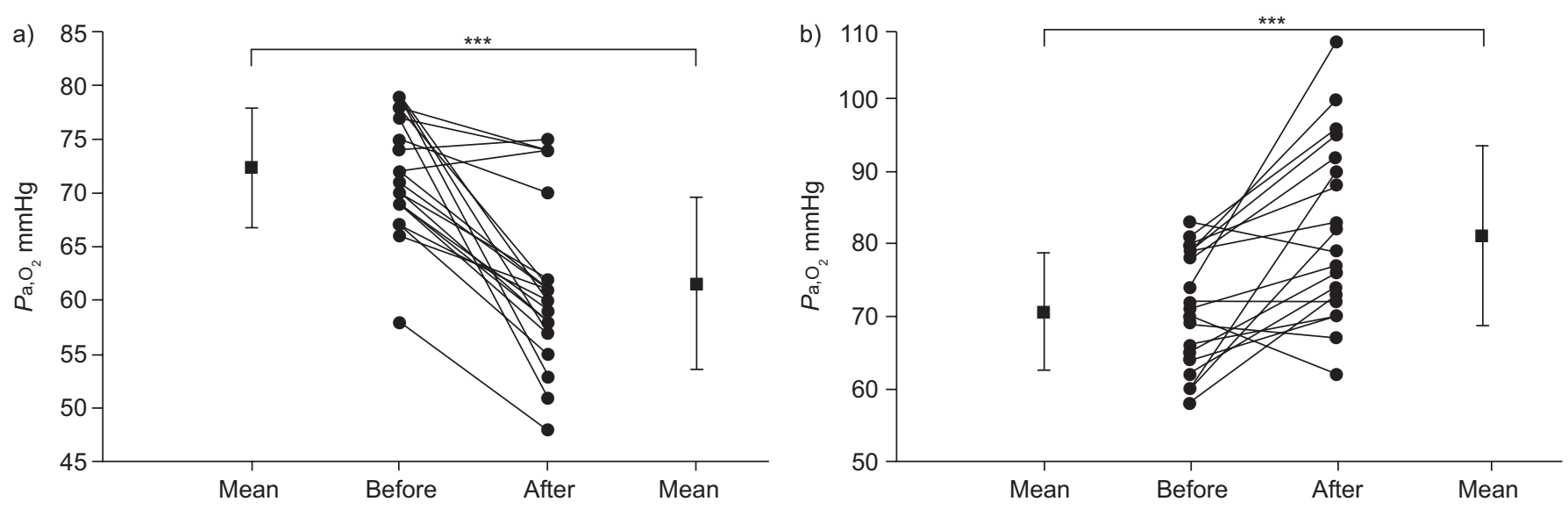

FIGURE 2. Changes in arterial oxygen tension $\left(\mathrm{Pa}_{1} \mathrm{O}_{2}\right)$ before and after 6-min walking test while on a) supplemental oxygen and b) noninvasive positive-pressure ventilation in addition to supplemental oxygen. The whiskers represent SD. ***: $p<0.001$

(Resmed, Sydney, NSW, Australia) was used in eight patients and an individually built full face mask was used in one patient; five patients received passive humidification.

$\mathrm{Pa}_{\mathrm{a}} \mathrm{O}_{2}$ substantially decreased by $1.43 \pm 1.06 \mathrm{kPa}(95 \% \mathrm{CI}-1.92-$ $-0.94 \mathrm{kPa} ; \mathrm{p}<0.001)$ during the $6 \mathrm{MWT}$ when supplemental oxygen was used, but markedly increased by $1.39 \pm 1.43 \mathrm{kPa}$ $(0.71-2.07 \mathrm{kPa} ; \mathrm{p}<0.001)$ when NPPV was used in addition to supplemental oxygen (table 2, fig. 2). $\mathrm{Pa}_{\mathrm{a}} \mathrm{CO}_{2}$ increased by $0.39 \pm 0.37 \mathrm{kPa} \quad(0.21-0.57 \mathrm{kPa} ; \mathrm{p}<0.001)$ during the $6 \mathrm{MWT}$ when supplemental oxygen was used, but did not significantly change when NPPV was used in addition to supplemental oxygen (table 2). BDS increased significantly during the 6MWT when receiving oxygen alone from 0 (IQR $0-0)$ to $6(4.5-10$; $\mathrm{p}<0.001)$, as well as during NPPV-aided walking from $0(0-0)$ to $4(1.5-4.5 ; \mathrm{p}<0.001)$. BDS after walking was significantly lower when walking was NPPV-aided compared with unaided walking ( $<<0.001$; table 2, fig. 3). Walking distance increased from 209 (IQR 178-279) to 252 (203-314) $\mathrm{m}$ ( $\mathrm{p}=0.027$; fig. 4) in favour of NPPV-aided walking.

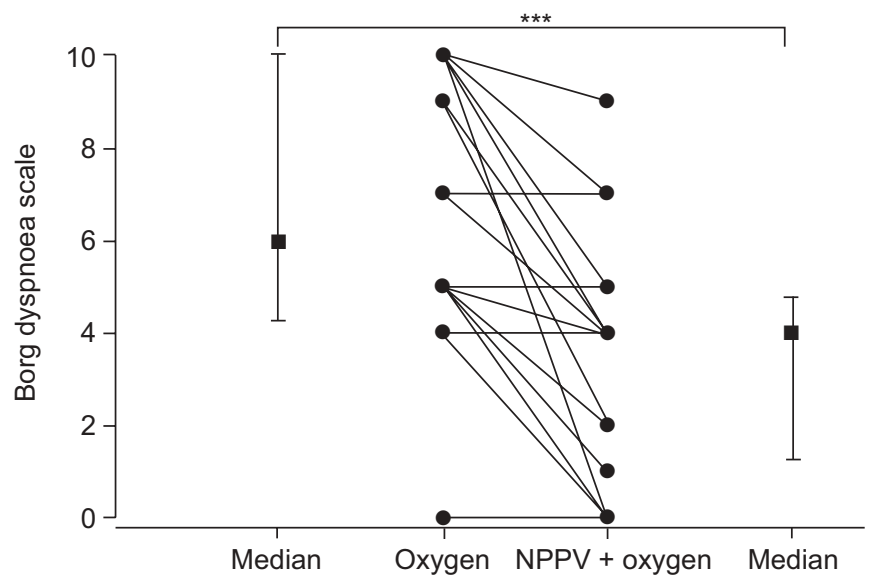

FIGURE 3. Borg dyspnoea scale following 6-min walking test while on supplemental oxygen and noninvasive positive-pressure ventilation (NPPV) in addition to supplemental oxygen. The whiskers represent the 25th-75th percentile values. ${ }^{* *}: p<0.001$.
After the 6MWT, the difference between NPPV-aided and unaided walking was $2.83 \pm 1.60 \mathrm{kPa}(95 \% \mathrm{CI} 2.07-3.59 \mathrm{kPa}$; $\mathrm{p}<0.001)$ for $\mathrm{Pa}_{1} \mathrm{O}_{2}$ and $3.0 \pm 2.9(1.6-4.4 ; \mathrm{p}<0.001)$ for BDS. Accordingly, there was no significant difference in $\mathrm{Pa}_{1}, \mathrm{CO}_{2}$.

\section{DISCUSSION}

The present study shows the impact of NPPV applied during walking on oxygenation in patients with end-stage hypercapnic COPD. $\mathrm{Pa}_{\mathrm{a}_{2}} \mathrm{O}_{2}$ substantially decreased during the $6 \mathrm{MWT}$ by a mean of $1.43 \mathrm{kPa}$ when only supplemental oxygen was administered, but markedly increased by a mean of $1.39 \mathrm{kPa}$ when NPPV was added to supplemental oxygen. In addition, the use of NPPV during walking resulted in significantly decreased dyspnoea on exertion with a significantly prolonged walking distance.

There are numerous former studies aimed at investigating the clinical effects of NPPV during exercise in patients with COPD. Most of these studies [7, 11-17], have concluded that NPPV during exercise is capable of reducing dyspnoea on exertion

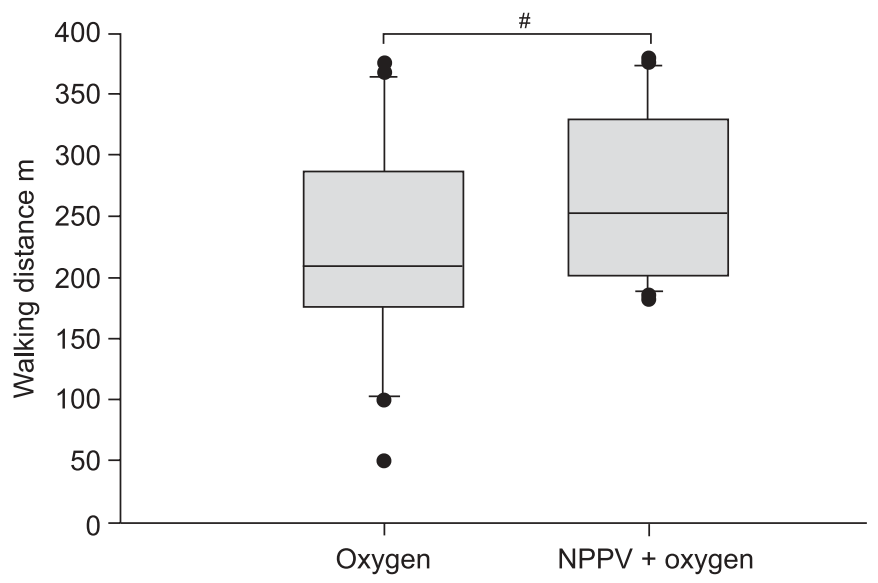

FIGURE 4. Walking distance after 6-min walking test while on supplemental oxygen and noninvasive positive-pressure ventilation (NPPV) in addition to supplemental oxygen. • : outliers. ${ }^{*}: p=0.027$. 
and improving exercise tolerance although contradictory results have also been published [26]. The present study differs substantially from previous studies in several aspects.

First, cycle ergometer testing $[7,12,16,17]$ or treadmill walking $[11,13]$ was used in the majority of previous studies. In contrast, a 6MWT was performed in the present study, as walking is suggested to more accurately reflect the exercise performance during daily activity in these patients [27]. In addition, a rollator was used, which had previously been shown to improve walking distance and to increase ventilatory capacity even without ventilatory support in COPD patients [28].

Secondly, patients included in the present study had more severe COPD compared with previous studies with a mean forced expiratory volume in one second (FEV1) of 27\% predicted and with dependence on long-term NPPV to treat hypercapnic CRF. Furthermore, patients were not studied during a rehabilitation programme, but during hospitalisation for a routine check of NPPV. Three patients were also evaluated for lung transplantation. Therefore, the present study indicates that NPPV during exercise is also beneficial for end-stage COPD patients who are already on NPPV at home.

Thirdly, oxygenation was not addressed in many of the former investigations. Desaturations during unaided exercise have been shown in patients with severe COPD [17] and pulmonary tuberculosis sequelae [18]. However, the present study is the first to demonstrate a fall in $\mathrm{Pa}, \mathrm{O}_{2}$ during simple walking, even when supplemental oxygen is applied in these patients, and a significant increase in $\mathrm{Pa}_{\mathrm{a}} \mathrm{O}_{2}$, even during walking, when NPPV is administered in addition to supplemental oxygen. The reason for this effect of NPPV remains unclear. $\mathrm{Pa}_{\mathrm{a}} \mathrm{CO}_{2}$ increased during walking with oxygen alone. However, the increase of $\mathrm{Pa}, \mathrm{O}_{2}$ during NPPV-aided walking is not sufficiently explained by augmentation of ventilation, since $\mathrm{Pa}_{\mathrm{a}} \mathrm{CO}_{2}$ remained unchanged with NPPV and oxygen. An improvement in ventilation-perfusion mismatch or pulmonary haemodynamics may have caused the beneficial effects on oxygenation, but this remains speculative. Another possibility could be the reduction of hyperinflation gained by NPPV, as previously shown elsewhere [29].

Fourthly, a completely different strategy of NPPV has been applied in the present study using higher inspiratory pressures and respiratory rates than previously reported. One study measuring endurance time and dyspnoea in patients with hypercapnic COPD [12], has indicated that proportional assist ventilation is superior to pressure support ventilation and continuous positive airway pressure indicating the impact of ventilatory modality on outcome parameters. In addition, recent studies have demonstrated that higher pressures (10 versus $5 \mathrm{cmH}_{2} \mathrm{O}$ ) for inspiratory pressure support resulted in larger improvements in exercise performance [16, 17]. In a more recent study [17], $\mathrm{Pa}_{\mathrm{a}} \mathrm{O}_{2}$ decreased during inspiratory pressure support aided $\left(10 \mathrm{cmH}_{2} \mathrm{O}\right)$ exercise. Therefore, higher ventilator settings, as chosen in the present study, are suggested to provide larger benefits on oxygenation during exercise.

It might be argued that these high ventilator settings are not easily tolerated by the patient. However, previous studies from the current authors' group have clearly shown that NPPV using high inspiratory pressures and high respiratory rates is well tolerated by the majority of these patients and provides beneficial physiological and clinical effects during short- and long-term use [20-22]. In addition, an increase in expiratory positive airway pressure was not applied in the present study, but this could provide further benefits in future studies in case of dynamic hyperinflation during exercise. The same is true for an increase in expiratory time, since the expiratory time was rather short in the present study.

The findings of the present study are suggested to have important clinical implications. NPPV can be applied during daily walking in addition to its use while at rest or during the night, thus alleviating dyspnoea during exertion and maintaining physical activity, which is highly important in severe COPD. This could be true both for palliative NPPV at home and for NPPV used for bridging to lung transplantation. Changes of ventilator settings or interface are not necessary to provide the beneficial effects of NPPV during walking. Therefore, the patient is autonomous and able to use NPPV during exertion in addition to its application during rehabilitation programmes, once the patient has been carefully established on HMV.

Importantly, the substantial improvement of oxygenation following NPPV-aided walking could prevent death from hypoxia-induced arrhythmias. Recently, it has been summarised that reduced FEV1 is an independent and important risk factor for cardiovascular mortality in patients with COPD [4]. Therefore, the risk for frequent or complex ventricular arrhythmia is substantially higher in patients with a lower FEV1/forced vital capacity ratio [4]. Furthermore, it has been suggested that hypoxaemia and oxygen desaturations contribute to myocardial dysfunction, heart failure and cardiac arrhythmia in patients with COPD [30,31]. End-stage COPD patients receiving HMV, like those in the present study, have severely reduced lung function parameters and severe desaturations during daily activities even if supplemental oxygen is given. Therefore, these patients are at high risk of death from cardiovascular complications. Although cardiac function and arrhythmias were not assessed in the present study, the present authors would strongly suggest that improving oxygenation during exertion as achieved by NPPV can presumably reduce cardiovascular complications, thus reducing mortality in patients with severe COPD [2-4]. Certainly, this needs further investigation.

Another clinical benefit shown in the present study is the increase in walking distance when using NPPV. Moreover, patients used NPPV during walking for the first time. Therefore, there is clearly room for further improvement in walking distance following full acclimatisation to NPPV during exercise. This shows that NPPV during exertion has the potential to improve physical activity in patients with CRF due to COPD.

It might be argued that the level of supplemental oxygen was not adapted to the exercise level, since increasing the dosage of supplemental oxygen has been shown to improve exercise ability in patients with severe COPD [32]. However, this was true for nonhypercapnic COPD patients only, and was felt to be disadvantageous in the present study, since a substantial 
increase in $\mathrm{Pa}, \mathrm{CO}_{2}$ had previously been shown even in patients with marginal ventilatory insufficiency [32]. Nevertheless, future studies should cautiously address the impact of an increased oxygen flow rate during exercise compared with NPPV-aided exercise in patients with severe hypercapnic COPD.

The present study has some limitations which need to be addressed. Unfortunately, blinding for both the patient and the investigator was not possible; however, it is unlikely that this has affected oxygenation. In addition, the underlying physiological mechanisms by which NPPV improved oxygenation have not been addressed. With this in mind, it should be acknowledged that the inspiratory fraction of oxygen could be different between NPPV-aided and unaided walking despite a similar flow rate due to a changed position of the oxygen source. However, changes according to these methodological inconsistencies are suggested to be minor in view of the substantial difference in oxygenation. Exercise performance during oxygen alone might also be somewhat artificially worse due to the fact that patients had to push the nonworking ventilator. Finally, the study was performed in hospital only and a 6MWT might not sufficiently address the conditions of patients at home with stairs and less space. Therefore, a conclusion for the practicality of routine NPPV during walking at home is premature. However, the current authors would suggest that the present findings will help design future physiological and clinical studies on ventilation-aided exercise in COPD patients with severe CRF. Furthermore, future studies should also address the impact of skeletal muscle impairment and should include subgroup analysis in order to identify patients who benefit from NPPV during walking compared with those who do not.

In conclusion, patients with severe chronic obstructive pulmonary disease receiving home mechanical ventilation can also easily use noninvasive positive-pressure ventilation during walking without changing ventilator settings or equipment. Arterial oxygen tension decreases during walking in these patients when only supplemental oxygen is given, but increases when noninvasive positive-pressure ventilation is added to supplemental oxygen. There is also significantly less dyspnoea and increased walking distance when noninvasive positive-pressure ventilation is used. Therefore, noninvasive positive-pressure ventilation could provide an additional role for palliative treatment of patients with hypercapnic chronic respiratory failure due to chronic obstructive pulmonary disease. In addition, noninvasive positive-pressure ventilation during exertion may prevent death from hypoxia-induced complications. Further studies are required to establish the role of noninvasive positive-pressure ventilation as a palliative treatment option during exertion in patients with severe chronic obstructive pulmonary disease.

\section{REFERENCES}

1 Soguel Schenkel N, Burdet L, de Muralt B, Fitting JW. Oxygen saturation during daily activities in chronic obstructive pulmonary disease. Eur Respir J 1996; 9: 2584-2589.

2 Huiart L, Ernst P, Suissa S. Cardiovascular morbidity and mortality in COPD. Chest 2005; 128: 2640-2646.
3 Hansell AL, Walk JA, Soriano JB. What do chronic obstructive pulmonary disease patients die from? A multiple cause coding analysis. Eur Respir J 2003; 22: 809-814.

4 Sin DD, Man SFP. Chronic obstructive pulmonary disease as a risk factor for cardiovascular morbidity and mortality. Proc Am Thorac Soc 2005; 2: 8-11.

5 Ambrosino N, Strambi S. New strategies to improve exercise tolerance in chronic obstructive pulmonary disease. Eur Respir J 2004; 24: 313-322.

6 Ambrosino N. Assisted ventilation as an aid to exercise training: a mechanical doping? Eur Respir J 2006; 27: 3-5.

7 Maltais F, Reissmann H, Gottfried SB. Pressure support reduces inspiratory effort and dyspnea during exercise in chronic airflow obstruction. Am J Respir Crit Care Med 1995; 151: 1027-1033.

8 Polkey MI, Kyroussis D, Mills GH, et al. Inspiratory pressure support reduces slowing of inspiratory muscle relaxation rate during exhaustive treadmill walking in severe COPD. Am J Respir Crit Care Med 1996; 154: 1146-1150.

9 Kyroussis D, Polkey MI, Hamnegard CH, Mills GH, Green M, Moxham J. Respiratory muscle activity in patients with COPD walking to exhaustion with and without pressure support. Eur Respir J 2000; 15: 649-655.

10 Polkey MI, Hawkins P, Kyroussis D, Ellum SG, Sherwood R, Moxham J. Inspiratory pressure support prolongs exercise induced lactataemia in severe COPD. Thorax 2000; 55: 547-549.

11 Keilty SE, Ponte J, Fleming TA, Moxham J. Effect of inspiratory pressure support on exercise tolerance and breathlessness in patients with severe stable chronic obstructive pulmonary disease. Thorax 1994; 49: 990-994.

12 Bianchi L, Foglio K, Pagani M, Vitacca M, Rossi A, Ambrosino N. Effects of proportional assist ventilation on exercise tolerance in COPD patients with chronic hypercapnia. Eur Respir J 1998; 11: 422-427.

13 Johnson JE, Gavin DJ, Adams-Dramiga S. Effects of training with heliox and noninvasive positive pressure ventilation on exercise ability in patients with severe COPD. Chest 2002; 122: 464-472.

14 van 't Hul A, Kwakkel G, Gosselink R. The acute effects of noninvasive ventilatory support during exercise on exercise endurance and dyspnea in patients with chronic obstructive pulmonary disease: a systematic review. J Cardiopulm Rehabil 2002; 22: 290-297.

15 Costes F, Agresti A, Court-Fortune I, Roche F, Vergnon J, Barthelemy JC. Noninvasive ventilation during exercise training improves exercise tolerance in patients with chronic obstructive pulmonary disease. J Cardiopulm Rehabil 2003; 23: 307-313.

16 van 't Hul A, Gosselink R, Hollander P, Postmus P, Kwakkel G. Acute effects of inspiratory pressure support during exercise in patients with COPD. Eur Respir J 2004; 23: $34-40$.

17 van 't Hul A, Gosselink R, Hollander P, Postmus P, Kwakkel G. Training with inspiratory pressure support in patients with severe COPD. Eur Respir J 2006; 27: 65-72.

18 Tsuboi T, Ohi M, Chin K, et al. Ventilatory support during exercise in patients with pulmonary tuberculosis sequelae. Chest 1997; 112: 1000-1007.

19 Sutherland ER, Cherniack RM. Management of chronic obstructive pulmonary disease. N Engl J Med 2004; 350: 2689-2697. 
20 Windisch W, Vogel M, Sorichter S, et al. Normocapnia during nIPPV in chronic hypercapnic COPD reduces subsequent spontaneous $\mathrm{Pa}_{\mathrm{a}} \mathrm{CO}_{2}$. Respir Med 2002; 96: 572-579.

21 Windisch W, Kostic S, Dreher M, Virchow JCJ, Sorichter S. Outcome of patients with stable COPD receiving controlled noninvasive positive pressure ventilation aimed at a maximal reduction of $\mathrm{Pa}, \mathrm{CO}_{2}$. Chest 2005; 128: 657-662.

22 Windisch W, Dreher M, Storre JH, Sorichter S. Nocturnal non-invasive positive pressure ventilation: physiological effects on spontaneous breathing. Respir Physiol Neurobiol 2006; 150: 251-260.

23 Windisch W, Hennings E, Sorichter S, Hamm H, Criee CP. Peak or plateau maximal inspiratory mouth pressure: which is best? Eur Respir J 2004; 23: 708-713.

24 Sciurba F, Criner GJ, Lee SM, et al. Six-minute walk distance in chronic obstructive pulmonary disease: reproducibility and effect of walking course layout and length. Am J Respir Crit Care Med 2003; 167: 1522-1527.

25 Borg GA. Psychophysical bases of perceived exertion. Med Sci Sports Exerc 1982; 14: 377-381.

26 Bianchi L, Foglio K, Porta R, Baiardi R, Vitacca M, Ambrosino N. Lack of additional effect of adjunct of assisted ventilation to pulmonary rehabilitation in mild COPD patients. Respir Med 2002; 96: 359-367.

27 Pitta F, Troosters T, Spruit MA, Decramer M, Gosselink R. Activity monitoring for assessment of physical activities in daily life in patients with chronic obstructive pulmonary disease. Arch Phys Med Rehabil 2005; 86: 1979-1985.

28 Probst VS, Troosters T, Coosemans I, et al. Mechanisms of improvement in exercise capacity using a rollator in patients with COPD. Chest 2004; 126: 1102-1107.

29 Diaz O, Begin P, Torrealba B, Jover E, Lisboa C. Effects of noninvasive ventilation on lung hyperinflation in stable hypercapnic COPD. Eur Respir J 2002; 20: 1490-1498.

30 Flick MR, Block AJ. Nocturnal versus diurnal cardiac arrhythmias in patients with chronic obstructive pulmonary disease. Chest 1979; 75: 8-11.

31 Tirlapur VG, Mir MA. Nocturnal hypoxemia and associated electrocardiographic changes in patients with chronic obstructive airways disease. N Engl J Med 1982; 306: 125-130.

32 Leach RM, Davidson AC, Chinn S, Twort CH, Cameron IR, Bateman NT. Portable liquid oxygen and exercise ability in severe respiratory disability. Thorax 1992; 47: 781-789. 